\title{
Management of constipation
}

\author{
High fibre diets work
Rodney Taylor
}

Constipation is a common symptom. Most definitions of constipation include infrequent bowel action - twice a week or less - that often require straining to pass hard faeces. Sensation of pain and incomplete evacuation are sometimes associated. ${ }^{1}$ In the early 1980 s general practitioner statistics showed that more than $\mathbf{4 0 0} 000$ patients annually attended with constipation as their main complaint. This $1 \%$ of the adult population is only a small proportion of those who suffer from constipation. Ten per cent of the British population are regularly constipated, rising from $3 \%$ in young adults to $20 \%$ or more in elderly people. ${ }^{2}$ Constipation is commoner in women than men because of slower intestinal transit. An additional similar percentage of people regularly take laxatives, aperients, or foods in their diet either to avoid constipation or in the belief that they need to keep their bowels "regular." In the United States, parts of northern Europe, and Japan the percentages are even greater, in contrast with Third World countries, where constipation is no problem.

\section{Fibre in the diet}

Change in dietary pattern is one of the main causes of the high prevalence of constipation in the Western world. Refining of food began in the Industrial Revolution. Since then there has been a steady fall in the consumption of starch and fibre with a corresponding increase in the intake of sugar, fat, and protein. In England in the $1860 \mathrm{~s} 66 \%$ of dietary energy came from carbohydrate, and $78 \%$ of this was starch. A hundred years later only $46 \%$ of energy came from carbohydrate, of which $56 \%$ was starch. Over this period there was a reciprocal rise in the prevalence of constipation. Dietary fibre comes from plant foods and is intimately related to starch. Refining processes extract fibre, increasing energy density and usually popular palatability. The intake of dietary fibre has been declining steadily from about $40 \mathrm{~g} /$ day 100 years ago to a current value of $15-20 \mathrm{~g} /$ day in most Western countries. Vegetarians may still consume 40 or more g/day, but many slimming diets provide less than $10 \mathrm{~g} /$ day. Traditional African diets as consumed by humans during their evolution as omnivores contain 50-150 g/day. Diets based on cereals, legumes, and root vegetables as the staple source of carbohydrate have the highest fibre content.

Dietary fibre is a portmanteau term for a widely diverse group of complex or non-starch carbohydrates of differing chemical structure and physical properties

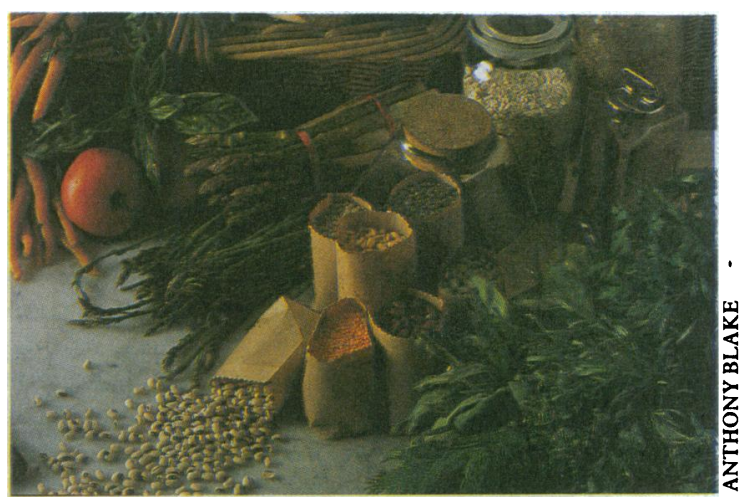

Cereals, legumes, and root vegetables have a high fibre content

that are not digestible by human intestinal enzymes. Cellulose and lignin are recognisably fibrous or particulate, whereas the non-cellulose polysaccharides (gums, mucilages, algal polysaccharides, pectins, and hemicelluloses) are soluble and largely viscous. In general, particulate fibres have the greatest effect on colonic function and viscous polysaccharides modulate absorption in the small intestine. A mixed high fibre diet will contain a wide selection of different fibres with differing properties and biological effects. It is not necessarily equivalent to a refined diet supplemented with bran.

\section{Effects on constipation}

Constipation is primarily a colonic problem. In the colon fibre increases stool bulk, holds water, and also acts as a substrate for colonic microflora, further increasing stool bulk by increasing bacterial, water, and salt content ${ }^{3}$ and producing hydrogen, methane, and other gases that augment the bulking effect. It decreases transit time, reduces intracolonic pressure, and produces a softer stool. ${ }^{4}$ All these effects are beneficial in relieving constipation, but the evidence comes mainly from studies on normal colons. An additional $20 \mathrm{~g} /$ day of bran increases faecal weight by $127 \%$ and decreases mean transit time by $41 \%$. The same quantity of cabbage, carrot, or apple fibre produces a smaller but similar effect. ${ }^{5}$ Large particles of bran give significantly greater increases in stool weight and water content with significantly shorter transit times than finely ground bran. ${ }^{6}$ Raw bran is more effective than processed bran. ${ }^{7}$ Transit time is reduced by fibre most noticeably in those with slow
Department of Gastroenterology, Royal Naval Hospital, Haslar, Gosport, Hampshire PO12 2AA

Rodney H Taylor, FRCP, professor of medicine

BrMed F 1990;300:1063-4

\section{EDITORIAL COMMENT}

These two articles represent not so much a controversy as a progression of treatment dependent on patient response. There is little doubt that a diet high in particulate fibre should alleviate constipation in many patients, but such diets are not particularly palatable and compliance is likely to be poor. When this approach fails it is appropriate to try other strategies, and it is noteworthy that stimulant laxatives do still have a place in the management of constipation, provided their use is limited in terms of both dose and frequency of administration. - PETER C RUBIN, professor of therapeutics, University of Nottingham 
intestinal transit and may increase in those with naturally rapid transit. ${ }^{8}$ Meta-analysis suggests that the same effects of bran in healthy controls are also found in patients with the irritable bowel syndrome, diverticular disease, and chronic constipation. Constipated patients, however, have lower stool weights and slower transit than normal subjects whether they take bran or not. ${ }^{9}$ Interestingly, not only plant fibre in the strict definition but also the fibrous content of meat in the carnivorous diet of Eskimos and even plastic particles have similar effects. ${ }^{40}$

Scientifically well controlled studies of the effects of increasing the intake of dietary fibre in the management of constipation are few. Most have studied the effects of added bran on stool weight, stool frequency, and transit time and have shown that subjects passed bulkier, softer stools more frequently with shorter transit times when taking bran. "An increased intake of all forms of dietary fibre has a similar effect, though there are even fewer controlled studies and much evidence is anecdotal.

Some constipated people find the secondary effects of fibre-namely, flatulence, distension, and bloating - sufficiently insufferable that they cannot tolerate enough fibre to alter constipated colonic function. ${ }^{12}$ Many of these effects reduce with time, probably owing to alterations in colonic microflora, and can be minimised by increasing fibre intake gradually. A small group of young women with "idiopathic slow transit constipation"13 and others with difficulty in rectal expulsion ${ }^{14}$ are not helped by an increased intake of fibre, but they are a tiny minority of those with constipation.

\section{Development of the bran wagon}

High fibre diets can help relieve constipation naturally in almost all patients, including those with the irritable bowel syndrome. The benefits may be limited by poor tolerance and by dietary inflexibility, particularly in elderly people for whom supplements may be better than changing eating habits. Fibre intake should probably be mixed and increased gradually over weeks or even months. Wheat bran is most effective in relieving constipation, though it is less palatable and often poorly tolerated by those used to a refined diet.
The benefits of wholemeal foods in constipation have been known since ancient times. Bran was identified as the essential factor in the nineteenth century by Allinson and subsequently by Kellogg, Dimock, and others. ${ }^{11}$ In the second world war Cleave carried out crucial clinical experiments at sea ${ }^{15}$ and subsequently stimulated the new wave of interest in fibre. ${ }^{16}$ Burkitt, Trowell, Painter, and others combined epidemiological and clinical observation to postulate the "fibre hypothesis," which attempted to attribute many Western illnesses in addition to constipation to a low intake of fibre or a high intake of refined carbohydrates. ${ }^{17}$ By the early 'seventies the bran wagon was rolling enthusiastically. Time has shown that not all claims for the benefits of high fibre diets can be substantiated ${ }^{18}$ but certainly in relieving constipation, high fibre diets work.

I Kamm MA. Constipation. Br f Hosp Med 1989;41:244-50.

2 Thompson WG, Heaton KW. Functional bowel disorders in apparently

healthy people. Gastroenterology 1980;79:283-8.
3 Stephen AM, Cummings JH. Mechanism of action of dietary fibre in the human colon. Nature 1980;284:283-4.
hephen AM, Cummings JH. Mechanis

4 Ornstein MH, Baird IM. Dietary fiber and the colon. Mol Aspects Med 1987;9:41-67.

5 Cummings JH, Southgate DAT, Branch W, Houston H, Jenkins DJA, James WPT. Colonic response to dietary fibre from carrot, cabbage, apple, bran and guar gum. Lancet 1978; i:5-9.

6 Heller SN, Hackler LR, Rivers JM, et al. Dietary fiber: the effect of particle size of wheat bran on colonic function in young adult men. Am $\mathcal{F}$ Clin Nutr 1980;33:1734-44.

7 Findlay JM, Smith AN, Mitchell WD, Anderson AJB, Eastwood MA Effects of unprocessed bran on colon function in normal subjects and in diverticular disease. Lancet 1974; ; 146-9.

8 Harvey RF, Pomare EW, Heaton KW. Effects of increased dietary fibre on intestinal transit. Lancet 1973;i:1278-80.

9 Müller-Lissner SA. Effect of wheat bran on weight of stool and gastrointestinal transit time: a meta analysis. $\mathrm{Br}$ Med $\mathcal{F}$ 1988;296:615-7.

10 Tomlin J, Read NW. Laxative properties of indigestible plastic particles. BrMed J 1988;297:1175-6.

11 Cranston D, McWhinnie D, Collin J. Dietary fibre and gastrointestinal disease. Br f Surg 1988;75:508-12.

12 Edwards CA, Tomlin J, Read NW. Fibre and constipation. Br 7 Clin Pract 1988;42:26-32.

13 Preston DM, Lennard-Jones JE. Severe chronic constipation of young women: "idiopathic slow transit constipation." Gut 1986;27:41-8.

14 Turnbull GK, Lennard-Jones JE, Bartram CI. Failure of rectal expulsion as cause of constipation: why fibre and laxatives sometimes fail. Lance 1986;i:767-9.

15 Cleave TL. Natural bran in the treatment of constipation. Br Med $\mathcal{f}$ $1941 ; \mathrm{i}: 461$.

16 Heaton KW. T L Cleave and the fibre story. Foumal of the Royal Nazal Medical Service 1980;66:5-10.

17 Trowell H, Painter N, Burkitt D. Aspects of the epidemiology of diverticular disease and ischemic heart disease. American foumal of Digestive Diseases 1974; 19:864-73.

18 Taylor RH. Bran yesterday ... bran tomorrow? Br Med f 1984;289:69-70.
University Hospital, Nottingham NG7 2UH Robin Spiller, MRCP, consultant gastroenterologist

\section{2 When fibre fails Robin Spiller}

Donald Burkitt's hypothesis that many of the ills of Western people, including constipation, were caused by a fibre depleted $\operatorname{diet}^{1}$ certainly caught the imagination of a generation. So much so that many patients currently consulting their general practitioner complaining of constipation will have already tried unsuccessfully some form of high fibre diet.

This lack of success is due either to intolerance or to ineffectiveness. Intolerance reflects the fact that high fibre foods are an acquired taste, require more chewing, and entail major changes in cooking habits that patients may find difficult to accept. Furthermore, some fibre supplements - for example, raw bran - are distinctly unpalatable. An effective dose of fibre $(20 \mathrm{~g})$ requires the ingestion of six tablespoonfuls of bran or two Weetabix and four large thick slices of wholemeal bread ( $300 \mathrm{~g}$ ) or their equivalent. Defective dentures and failing appetite or imagination may make such an increase in intake unacceptable. Purified fibre supplements such as ispaghula (Fybogel) or sterculia
(Normacol) may be more acceptable for such patients in producing a softer, bulkier stool that is easier to pass. Lactulose is also effective, though rather expensive, and its oversweet taste does not appeal to everyone. Those who do successfully increase their intake of fibre, by whatever means, often experience the effects of increased bacterial colonic fermentation with accompanying flatulence, abdominal distension, and colic, which in some patients are sufficiently severe to lead to discontinuation of treatment. ${ }^{2}$

\section{Alternative approaches}

Although high fibre diets are undoubtedly effective in those with normal colonic function, unfortunately, those with slow transit who are likely to need the most help tend to show the least effect. ${ }^{3}$ A slow transit seems to favour a more complete bacterial degradation of fibre in the right colon, thus minimising the effect of fibre on faecal output. Furthermore, after a few weeks 